It has been suggested elsewhere ${ }^{8}$ that the geochemical significance of fixation by non-legume nodules must not be overlooked. For example, in New Zealand, which is recognized as deficient in native legumes, the widespread species of Coriaria are possibly the main native source of symbiotically fixed nitrogen. The present discontinuous distribution of the genus, noted above, probably indicates that in former times the genus was represented in many regions from which it has now disappeared, and was thus in a position to contribute to the supply of combined nitrogen for plant life in general in many areas.

Botany Dept.,

G. BOND

The University, Glasgow.

June 12.

${ }^{1}$ Bond, G., Fletcher, W. W., and Ferguson, T. P., Plant and Soil, 4. 309 (1954).

2 Bond, G., Ann. Bot., N.S., 21, 513 (1957),

${ }^{3}$ Kataoka, T., Jap. J. Bot., 5, 209 (1930).

- Good, R., New Phytol., 29, 170 (1930).

S Shibata, K., and Tahara, M., Bot. Mag. Tokyo, 31, 157 (1917).

- MacConnell, J. T., and Bond, G., Ann. Bot., N.S., 21, 185 (1957)

Coriaria myrtifolia, the only species of the genus occurring in the western Mediterranean region, is extraordinarily abundant in the less dense woodlands of the Spanish provinces of Gerona and Barcelona (eastern part) at altitudes of $200-600 \mathrm{~m}$., reaching occasionally to $1,000 \mathrm{~m}$. and also descending in gullies to sea-level. It is more localized in the provinces of Lérida and Tarragona, and rare in more southerly provinces. It occurs, but is not now regarded as native, in Portugal ${ }^{1}$. The species reappears in the western Rif and Algeria, and also in the island of Ibiza ${ }^{2}$, while in southern France it extends from the Gironde to the Alpes Maritimes, penetrating into Italy as far as part of the Apennines. Its occurrence in Sicily and Greece is doubtful.

On examining the root systems of young plants of C. myrtifolia in two localities, in the provinces of Barcelona and Lérida respectively, clearly evident root nodules were observed, resembling closely those described for Japanese material ${ }^{8}$ and others shown in photographs provided by Dr. Bond of New Zealand material. Difficulty was experienced in locating the nodules on old plants.

It may be added that the species attains its optimal development in the humid climates where Quercus ilex is dominant. It prefers strong clay soils and is markedly heliophilous, being found especially along the borders of roads, streams and woodland; it is commonly associated with Prunus spinosa and species of Rubus and Clematis, and de Bolós ${ }^{4}$ has provided a full ecological study of the RubetoCoriarietum association.

The fertility of soils where $C$. myrtifolia occurs plentifully is an accepted fact. In some evergreen oak woods the species makes a complete ground cover, and could be of some importance in forest economy if appreciable fixation of nitrogen occurs in the root nodules. It may be noted that thousands of tons of leaves of $C$. myrtifolia were formerly collected each year for use in tanning leather.

\section{Pedro Montserrat}

Instituto de Biología Aplicada,

Universidad de Barcelona. May 17.

` Pinto da Silva, A. R., Agronomia Lusitana, 8, 14 (1946).

¿ Knoche, H., "Flora balearica", 2, 167, and 3, 175 (Montpellier, 1922-23).

S Kataoka, T., Jap. J. Bot., 5, 209 (1930).

- Bolós, O. de, Collectanea Botanica, 4, 274 (1954).

\section{Fluorescent Pigment of Microsporum}

IN a previous communication, Wolf ${ }^{1}$ reached the conclusion that the fluorescent pigment produced by Microsporum canis Bodin and $M$. gypseum Guiart and Grigorakis was a pteridine. The fluorescent substance was extracted from cultures of both fungi grown in vitro upon hair and on a synthetic medium. The conclusion as to the pteridine nature of the pigment was based upon ultra-violet absorption spectra, fluorescence spectra, and paper chromatography of a purified material, and is consistent with the results of earlier chemical studies ${ }^{2,3}$.

Since then, Chattaway and Barlow 4 have challenged this conclusion, without however adding any new evidence, and have raised questions concerning the nature of fluorescent materials in uninfected hair and in naturally infected hair which neither they nor ourselves can answer at the present time. Recently, Rebell et al..$^{5}$ have shown that the fluorescent material of rat hair is $l$-kynurenine, but the nature of the fluorescent substance in human hair has not been established. It is the purpose of this communication to present additional evidence as to the pteridine nature of the Microsporum pigment derived from infra-red studies and bioassay.

Cultures of Microsporum canis and M. gypseum, grown upon hair and upon a synthetic medium, were extracted with water by autoclaving for $15 \mathrm{~min}$. The fluorescent material was adsorbed on charcoal, eluted with methanol, and passed through a column of alumina as previously described ${ }^{1}$. The methanol extracts were evaporated to dryness, and potassium bromide pellets containing the fluorescent substance were examined in the infra-red with a Perkin-Elmer model 21 spectrophotometer. The spectra are shown in Fig. 1.

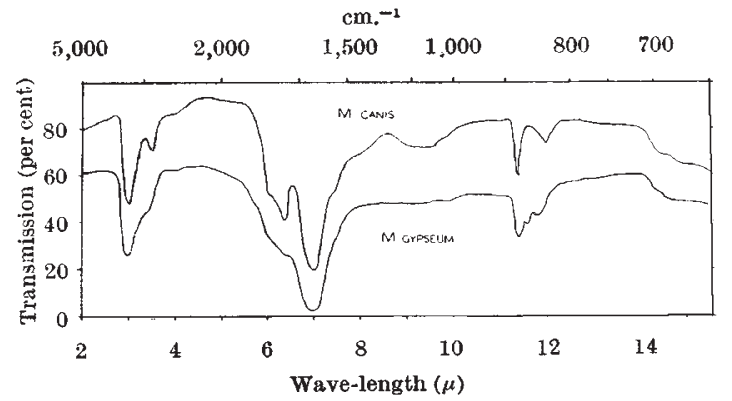

Fig. 1. Infra-red absorption spectra of the fluorescent pigments of Microsporum canis and $\boldsymbol{M}$. gypseum

For $M$. canis, the absorption maxima found were as follows: there was a large peak at $3,375 \mathrm{~cm} .^{-1}$, indicating an $-\mathrm{OH}$ or an $=\mathrm{NH}$ group, a small peak at 2,875 (possibly $\mathrm{C}-\mathrm{H}$ ), a shoulder at $1,700\left(-\mathrm{CONH}_{2}\right)$, a medium peak at $1,580\left(-\mathrm{NH}_{2}\right)$, a large peak at 1,440 (possibly $\mathrm{C}-\mathrm{H}$ ), a shoulder at $1,380\left(-\mathrm{CONH}_{2}\right)$, a broad peak at $1,040-1,100\left(-\mathrm{NH}_{2}\right)$, a large peak at 880 and a small one at $840 \mathrm{~cm}^{-1}$ (both of $\mathrm{C}-\mathrm{H}$ ).

The spectrum for $M$. gypseum was quite similar. There was a large peak at $3,375 \mathrm{~cm} .^{-1}$, a shoulder at 2,950 , a shoulder at 1,580 , a large peak at 1,440 , a shoulder at 1,350 , a large peak at 880 and small peaks at 865 and $855 \mathrm{~cm} .^{-1}$. The relatively small number of peaks appears to us to refute the objection of Chattaway and Barlow ${ }^{4}$ that our methods of preparation "would almost certainly not effect any great purification of the fluorescent material", and further indicate that our preparations had a purity 